\title{
Selenium and thyroid health in NZ European women
}

\author{
Ljiljana Jowitt* \\ Faculty of Health and Environmental Sciences, School of Interprofessional Health Studies, AUT University, New Zealand
}

\begin{abstract}
The primary aim of the study was to determine differences in the hormonal status (TSH, T3, and T4) between healthy participants and participants with Hashimoto's thyroiditis. The secondary aim of the study was to assess plasma selenium nutritional status and its relationships with the serum levels of thyroid hormones in both of the groups. This study is a pilot and a cross-sectional. Study participants were assigned into two groups, the control group with healthy participants (n=13) and a group of women with Hashimoto's thyroiditis $(n=8)$. Any change in the participants' daily routine was not required. For the measurement of plasma selenium, thyroid stimulating hormone, tetra iodothyronine, and triiodothyronine, creatinine, and glomerular filtration rate, participants' non-fasting blood samples were taken. Two women with subclinical hypothyroidism were excluded from the statistical data analyses. Women with Hashimoto's thyroiditis were older, had higher tetra iodothyronine level, low triiodothyronine/tetra iodothyronine ratio, higher plasma selenium levels, and similar triiodothyronine plasma levels to women in the control group. Significant relationships between triiodothyronine and selenium, triiodothyronine were identified in the group of women with Hashimoto's thyroiditis. There was a moderate selenium deficiency in both of the groups that affected more women with hypothyroidism. Compromised peripheral deiodination in women with hypothyroidism required increased L-thyroxine dosing, which in turn increased the level of tetra iodothyronine, and decreased pituitary thyroid stimulating hormone, in order to achieve the desired level of the triiodothyronine. In order to increase plasma selenium level, recent research has suggested that selenium supplementation with selenomethionine or selenium selenite, might also slow down the process of thyroid destruction by thyroid autoantibodies in Hashimoto's thyroiditis. In the past, the process of selenium supplementation had variable success rates. Therefore, further research is warranted.
\end{abstract}

Abbreviations: TSH: Thyroid stimulating hormone; T3: Triiodothyronine; T4: Tetraiodothyronine; SeMet: Selenomethionine; SeCys: selenocysteine

\section{Introduction}

Prevalence estimates of primary hypothyroidism worldwide range from $1 \%$ to $10.3 \%$, and for hyperthyroidism from $0.5 \%$ to $2.5 \%$ [1]. There are limited data on the prevalence and type of thyroid disease (TD) in New Zealand community. Hamilton study, which included 662 patients in general practice, estimated the overall prevalence of TD in women of about $4.8 \%$, and about $1.1 \%$ in men. Hence, women were 4.5 times more likely than men to have TD. New Zealand European ethnic group had the greatest prevalence of TD of 3.5\%, then the Maori ethnicity of $2.1 \%$, Pacifica peoples of $1.8 \%$, Asians $1.8 \%$, and other ethnic groups of $2.0 \%$. Of those with TD, hypothyroidism diagnosed in $2.5 \%$ in the Hamilton study population, while in general practice hypothyroidism accounted for $78.9 \%$ of diagnosed thyroid diseases. These data are comparable (with $3.1 \%$ of TD in adults) with national and international literature, with TD being more prevalent in women and in elderly.

Thyroid hormone secretion is regulated by the hypothalamicpituitary-thyroid axis ic (HPT axis), through stimulatory actions of thyrotropin-releasing hormone (TRH) and thyroid-stimulating hormone (TSH) [2]. TSH stimulates the thyroid gland to synthesize tetra iodothyronine (T4) and triiodothyronine (T3). T4 is synthesized entirely by the thyroid gland and acts as a prohormone to generate $\mathrm{T} 3$, which is required for normal growth and development, and energy homeostasis, and $\mathrm{O} 2$ consumption in tissue cells. Conversion of T4 to $\mathrm{T} 3$ in body tissues provides negative feedback at the level of both anterior pituitary and the hypothalamus [3].

The thyroid gland has a high tissue concentration of the essential nutritional trace element selenium (Se), more than the liver or any other organ or a tissue in the body [4]. Selenium plays a crucial role in the maintenance of metabolic, immune-endocrine, and cellular homeostasis, owing to its antioxidant and anti-inflammatory properties [5]. Biological actions of selenium are mostly mediated through the expression of at least 30 selenoproteins, coded by 25 genes that have $21^{\text {st }}$ amino acid selenocysteine at their active centre [6]. The essential role of selenoproteins is in their involvement in peroxide degradation, cellular redox and transcription regulation, thyroid hormone deiodination, and spermatogenesis $[7,8]$. The major selenoproteins, expressed in the thyroid gland are glutathione peroxidases (GPXs), thioredoxin reductase (TRs), and deiodinases (Ds) $[9,10]$. The process of thyroglobulin ( $\mathrm{Tg}$ ) iodination is catalyzed by selenoenzyme thyroid peroxidase (TPO), which requires higher hydrogen peroxide $(\mathrm{H} 2 \mathrm{O} 2)$ concentration generated by the thyrocytes $[11,12]$. Selenoenzymes GPXs prevent lipid peroxidation and protect the cell membranes from oxidative damage. The GPX1 is one of the most abundant selenoenzyme and is highly sensitive to selenium deficiency $[13,14]$.

Selenoenzymes deiodinases are present in the thyroid gland and all body tissues [15]. At the cellular level, thyroid hormone signalling can change, owing to local activation and inactivation of thyroid hormone via deiodination pathways inside the target cells [16-18]. The type 1

Correspondence to: Ljiljana Jowitt, Faculty of Health and Environmental Sciences, School of Interprofessional Health Studies, AUT University, 90 Akoranga Drive, North Shore Campus, AF 416, PO Box 92006, 1142, Auckland, New Zealand, Tel: +649 9219999 extension 8096; Email: ljowitt@aut.ac.nz

Key words: New Zealand, selenium, Hashimoto's autoimmune thyroiditis, L-thyroxine

Received: April 16, 2017; Accepted: May 04, 2017; Published: May 08, 2017 
deiodinase (D1) and type 2 deiodinase (D2) increase cellular thyroid activity by converting prohormone $\mathrm{T} 4$ to the activeT3, whereas the type 3 deiodinase (D3) reduces cellular thyroid activity by converting $\mathrm{T} 4$ to reverse $\mathrm{T} 3$, and of $\mathrm{T} 3$ to $3,3^{\prime}$-diiodothyronine (T2) $[19,20]$. These pathways control thyroid hormone bioavailability and bioactivity at various levels of cellular organization, and their effects are far less understood [21].

Selenium acts as an antioxidant in plasma and extracellular fluids, where selenium as amino acid selenocysteine is incorporated into selenoprotein $\mathrm{P}$ and is carried bound to albumin as selenomethionine (SeMet) [22, 23]. The liver secretes the most of the selenoproteins, and is the main site of selenium metabolism and homeostasis.

Selenoprotein P (SEPP1) and GPX3 are present in human plasma and can be used as a biomarker of selenium nutritional status [24]. Measurements of SEPP1 and GPX3 in plasma can identify the risk of selenium nutritional deficiency. According to Xia and co-authors [25], SEPP1 is the best plasma biomarker, because its optimization required a larger selenium intake than did a GPX3 activity. In selenium deficiency, the synthesis of some selenoenzyme such as glutathione peroxidase is prioritized over that of others [26,27]. Changes in selenium status may affect immune response, neurodegeneration, cardiovascular disease, and cancer [28].

\section{Selenium intake in New Zealand population}

According to the 2008/09 New Zealand Nutrition Survey (NZANS) which collected information from 4721 adults New Zealanders aged 15 years and over, selenium intakes increased from 1997 to 2008/09. Se intakes were still inadequate for about one-third of males (31.5\%) and over half $(58.2 \%)$ of females [29]. The median usual daily selenium intake was $67.0 \mu \mathrm{g}$ for males, and $47.1 \mu \mathrm{g}$ for females. Elderly population, both males and females aged $71+$ years $(52.0 \mu \mathrm{g}$ and 39.5 $\mu \mathrm{g}$, respectively), and females aged $15-18$ years $(38.7 \mu \mathrm{g})$ had lower selenium intakes than 31-50-year-old males and females $(78.0 \mu \mathrm{g}$ and $51.9 \mu \mathrm{g}$, respectively). In New Zealand, the recommendation for selenium intake should be on average $60 \mu \mathrm{g}$ per day for men and $53 \mu \mathrm{g}$ per day for women, to achieve the maximal activity of GPXs in plasma or erythrocytes [30].

The major source of selenium in New Zealand is bread (15\%), followed by fish and seafood (12\%), and poultry (10\%). Intakes of Se in New Zealand have improved after increased importation of highSe Australian and other imported wheat. Fruit, vegetables, and grains are grown in New Zealand have lower selenium levels than plant foods from other countries with a soil higher in selenium levels [31, 32].

The primary aim of the study was to determine differences in the hormonal status (TSH, T3, and T4) between healthy participants and participants with Hashimoto's thyroiditis. The secondary aim of the study was to assess Se nutritional status and its relationships with the serum levels of thyroid hormones in both control and hypothyroid group on medication with L-thyroxine.

\section{Patients and method}

This study is a pilot study, crossectional, and observational study. Participants in the study were self - assigned into two groups, control group with healthy participants, and a group of women with Hashimoto's thyroiditis (HT) on medication with L-thyroxine. Any change in the participants' daily routine was not required. The plasma selenium, TSH, T4, T3, creatinine and e-GFR (Glomerular Filtration Rate) was determined in women in both groups, and compared with gold standards. Plasma TSH, T3, and T4 were measured using competitive immunoassays technique by the LabTests Laboratories in Auckland. Serum selenium was measured using inductively coupled plasma -dynamic reaction cell mass spectrometry by the Canterbury Health Laboratories in Christchurch, New Zealand. Data on the antithyroperoxidase (anti-TPO) antibodies were not available in women with HT.

\section{Statistical analyses}

Data were analysed by the SPSS for windows (version 22.0, SPSS Inc., Chicago, Illinois, USA). Owing to the small sample size, nonparametric tests were used for data analysis. Descriptive statistics and correlation analyses were used in order to determine relationships among variables. The results of plasma contents concentrations were expressed as the mean \pm standard deviation. Values with a $\mathrm{p}<0.05$ were taken as significant.

\section{Results}

The study sample consisted of eight women with HT on medication with L-levothyroxine, and 12 women in a good health in the control group. Two women, diagnosed with subclinical hypothyroidism, were excluded from statistical data analysis. Women with HT were older, had lower plasma TSH levels, lower T3/T4 ratio, and higher T4 and selenium levels (Table 1). Plasma T3 levels were almost identical in both groups. The values of creatinine and e-GFR were within the optimal range in both groups.

There was a significant positive relationship between age and $\mathrm{T} 4$ $\left(\mathrm{p}<0.01\right.$, Spearman's rho $\left.=0.926^{* *}\right)$, and T3 and selenium $(\mathrm{p}<0.02$, Spearman's rho $\left.=0.778^{\star}\right)$ in hypothyroid women. In addition, there was a positive relationship between T3 and the T3/T4 ratio $\left(p<0.01\right.$, Spearman's rho $\left.=0.794^{\star}\right)$. Significant negative relationship between creatinine and e-GFR $\left(\mathrm{p}<0.007\right.$, Spearman's rho $\left.=-0.851^{\star *}\right)$ was identified in hypothyroid group and control group $(\mathrm{p}<0.000$, Spearman's rho $\left.=-0.843^{\star *}\right)$.

In the control group, there was a significant positive relationship between T3 and the T3/T4 ratio $\left(\mathrm{p}<0.008\right.$, Spearman's rho $\left.=0.701^{\star *}\right)$ and significant positive relationship between $\mathrm{T} 4$ and the $\mathrm{T} 3 / \mathrm{T} 4$ ratio $\left(\mathrm{p}<0.03\right.$, Spearman's rho $\left.=0.600^{*}\right)($ Table 2$)$.

The values of the variables for both, the control group and hypothyroid group on medication, were distributed into $10^{\text {th }}, 25^{\text {th }}, 50^{\text {th }}$ and $75^{\text {th }}$ percentiles (Table 3 ).

\section{Discussion}

In this study, with a relatively small sample size $(n=23)$, participants were European women with the mean age of $53.50 \pm 7.76$ in the control

Table 1. Descriptive statistics (mean $\pm \mathrm{SD}$ ).

\begin{tabular}{|c|c|c|c|c|c|}
\hline & & \multicolumn{2}{|c|}{ Control group $n=13$} & \multicolumn{2}{|c|}{$\begin{array}{l}\text { Group on medication } \\
n=8\end{array}$} \\
\hline & & Mean \pm SD & Range & Mean \pm SD & Range \\
\hline Age & & $52.69 \pm 7.39$ & $37-64$ & $58.00 \pm 6.74$ & $48-65$ \\
\hline \multicolumn{6}{|c|}{ Reference range } \\
\hline TSH & $0.30-4.00 \mathrm{mIU} / \mathrm{L}$ & $2.06 \pm 0.41$ & $1.40-2.90$ & $1.55 \pm 1.02$ & $0.63-3.30$ \\
\hline $\mathrm{T} 4$ & $10.0-20.0 \mathrm{pmol} / \mathrm{L}$ & $14.61 \pm 1.44$ & $12.00-17.00$ & $15.50 \pm 1.41$ & $14.00-18.00$ \\
\hline T3 & $3.0-6.5 \mathrm{pmol} / \mathrm{L}$ & $4.76 \pm 0.58$ & $3.90-6.10$ & $4.46 \pm 0.72$ & $3.50-6.00$ \\
\hline T3/T4 ratio & $0.30-0.325$ & $0.33 \pm 0.05$ & $0.26-0.44$ & $0.29 \pm 0.06$ & $0.23-0.43$ \\
\hline Selenium & $0.45-1.40 \mathrm{umol} / \mathrm{L}$ & $1.28 \pm 0.15$ & $1.00-1.52$ & $1.35 \pm 0.17$ & $1.16-1.69$ \\
\hline Creatinine & $45-90 \mathrm{umol} / \mathrm{L}$ & $67.69 \pm 8.66$ & $51.00-82.00$ & $66.37 \pm 10.36$ & $49.00-84.00$ \\
\hline e-GFR & $>90 \mathrm{~mL} / \mathrm{min} / 1.73 \mathrm{~m}^{2}$ & $85.69 \pm 6.55$ & $69.00-90.00$ & $84.37 \pm 9.47$ & $64.00-90.00$ \\
\hline
\end{tabular}


Table 2. Relationships between variables in the hypothyroid group (Spearman's rho).

\begin{tabular}{|c|c|c|c|c|c|c|c|}
\hline & Age & TSH & T3 & T4 & Selenium & Creatinine & GFR \\
\hline \multirow[t]{2}{*}{ TSH } & -.491 & & & & & & \\
\hline & .217 & & & & & & \\
\hline \multirow[t]{2}{*}{$\mathrm{T} 3$} & -.066 & .228 & & & & & \\
\hline & .876 & .588 & & & & & \\
\hline \multirow[t]{2}{*}{$\mathrm{T} 4$} & $.926^{* *}$ & -.442 & -.173 & & & & \\
\hline & .001 & .273 & .682 & & & & \\
\hline \multirow[t]{2}{*}{ Selenium } & .156 & .381 & $.778^{*}$ & .147 & & & \\
\hline & .713 & .352 & .023 & .728 & & & \\
\hline \multirow[t]{2}{*}{ Creatinine } & -.476 & -.120 & -.313 & -.395 & -.395 & & \\
\hline & .233 & .778 & .450 & .333 & .333 & & \\
\hline \multirow[t]{2}{*}{ GFR } & .000 & .518 & .535 & -.070 & .546 & $-.851^{* * *}$ & \\
\hline & 1.000 & .188 & .172 & .869 & .162 & .007 & \\
\hline \multirow[t]{2}{*}{ T3T4ratio } & -.606 & .422 & $.794^{*}$ & -.671 & .398 & .085 & .331 \\
\hline & .111 & .298 & .019 & .069 & .329 & .842 & .423 \\
\hline
\end{tabular}

*Significant findings

**. Correlation is significant at the 0.01 level (2-tailed).

*. Correlation is significant at the 0.05 level (2-tailed).

group and $56.33 \pm 7.16$ in the group of women with a long-standing HT (Table 1). Two women identified with subclinical hypothyroidism were excluded from data analysis. Plasma T3 and T4 levels were within optimal range, whereas plasma TSH levels were $10 \mathrm{mIU} / \mathrm{L}$ and $4.7 \mathrm{mIU} / \mathrm{L}$ respectively. Accordingly, subclinical hypothyroidism is characterized with normal T3 and T4 plasma levels and elevated TSH [33, 34]. Among the experts, there is agreement that subclinical hypothyroidism is an early mild failure of thyroid function [35,36]. The hormonal pattern associated with the subclinical hypothyroidism is a compensated state in which high plasma TSH serves to maintain normal thyroid hormone levels. The standard medication for subclinical hypothyroidism and life-long management of hypothyroidism is a hormone replacement therapy of a single daily dose of L-thyroxine [37]. According to the American Thyroid Association (ATA), the goal of therapy with L-thyroxine is to restore clinically and biochemically a euthyroid state in patients. The usual dose of levothyroxine is 1.6 to $1.8 \mu \mathrm{g} / \mathrm{kg}$ per day, while elderly patients require a smaller dose of $1 \mu \mathrm{g} / \mathrm{kg}$ per day or even less, in relation to age, weight and cardiac status.

The results of the study demonstrated that plasma TSH, T4, and T3 levels, and T3/T4 ratios between the two groups differed. Mean plasma TSH levels were slightly lower in women with HT, being $1.55 \pm 1.02$ and $2.06 \pm 0.41$ respectively, although the recommendation by ATA was to aim for a TSH in the lower half of the normal range (0.4 - 4.5 $\mathrm{mIU} / \mathrm{L}$.), around $2.5 \mathrm{mIU} / \mathrm{L}$ in patients with primary hypothyroidism [38]. The two study participants' TSH levels were closer to the lower end of the normal range, being $0.63 \mathrm{mlU} / \mathrm{L}$ and $0.81 \mathrm{mlU} / \mathrm{L}$ respectively (less than $0.1 \mathrm{mIU} / \mathrm{L}$.), which were attributed to the L-thyroxine overtreatment. Studies proved, that chronic maintenance of TSH below the optimal reference range might be associated with atrial fibrillation, osteoporosis, and bone fractures [39-41]. On the other hand, TSH levels maintained above the normal range might cause the development of metabolic dysfunction [42]. The initial treatment with L-thyroxine in hypothyroidism requires TSH level monitored every six to eight weeks with adjustment of the L-thyroxine dosing [43]. Once the TSH has stabilized, semi-annual or annual testing is required [44].

Further, the mean plasma T3 levels were almost identical in both groups, being $4.76 \pm 0.58$ and $4.46 \pm 0.72$ respectively, whereas plasma T4 levels were significantly higher in the hypothyroid group than in the control group $(15.50 \pm 1.41$ and $14.61 \pm 1.44$ respectively). Increased $\mathrm{T} 4$, and a slight decrease in plasma TSH $(1.55 \pm 1.02)$, and the T3/T4 ratio $(0.29 \pm 0.06$ and $0.33 \pm 0.05$ respectively) in the hypothyroid group indicated that in order to achieve normal T3 levels, higher doses of L-thyroxine should be given to patients [45]. In support of these findings, the study by Mortoglou and Candiloros (2004) demonstrated a similar case scenario, where hypothyroid patients were given a higher dose of L-thyroxine in order to maintain average plasma T3 levels [46].

In women with $\mathrm{HT}$, there was a significant positive relationship between plasma selenium and T3 $(p<0.05$, and Spearman's rho was 0.778). In this relationship, both variables have a tendency of rising, meaning that $\mathrm{T} 3$ production will increase if selenium plasma levels increase. Selenium deficiency inhibits the conversion of T4 to T3 by both selenoenzyme, type I and type II deiodinases. During the process of deiodination, selenium in the form of SeCys has a dominant role, which underlines the dependency of type 1 and types 2 deiodinases' activity on plasma selenium levels [47]. However, in the present study baseline plasma selenium levels were higher in women with HT (1.35 \pm 0.17 ), than in the control group $(1.28 \pm 0.15)$, and also were higher than the baseline selenium levels recommended by Thomson and coauthors [48]. According to Thomson et al. plasma selenium levels of $0.82-0.90 \mu \mathrm{gmol} / \mathrm{L}$ should be adequate for optimal function of deiodinases. However, Karunasinghe et al. [49] have suggested that the basic selenium requirement may vary with genotype for a number of variations in selenoprotein genes, suggesting that an effective dietary selenium intake for one person may be different from that for others. In the absence of this information, recommended plasma selenium levels should be in the range of $1.27-1.90 \mu \mathrm{mol} / \mathrm{L}$.

Selenium plasma levels were based on the measurement of SEPP1 which is the most reliable biomarker of selenium status, and its full expression requires a significantly higher selenium dose [50]. SEPP1 and selenoenzyme deiodinases rank high in the hierarchy of selenium supply, and cannot be affected by marginal selenium deficiency like GPx [51]. Maximal activity of selenoenzyme is reached at blood selenium levels above $1.27 \mu \mathrm{mol} / \mathrm{L}$, or according to the recent research by Rayman [52], plasma selenium levels in the range of 1.6 to $1.9 \mu \mathrm{mol} / \mathrm{L}$ are considered optimal for thyroid and overall good health. However, in relation to optimal plasma selenium levels, there is an agreement between those two studies by Rayman (2012) and Karunasinghe and co-authors (2012). Plasma selenium levels were slightly higher in the hypothyroid group than in the control group, with the mean plasma selenium levels closer to the lower end of the optimal range $(1.28 \pm 0.15$ and $1.35 \pm 0.17$ respectively), which might be explained by different diet in those affected.

Hashimoto's thyroiditis is part of the spectrum of autoimmune thyroid diseases which cluster in families [53]. It displays an organized lymphocytic infiltration that leads to thyrocytes apoptosis, and to thyroid fibrosis with age [54]. This draws attention to hypothyroid women in the study, who were older than women in the control group were, and who had TSH, T3, and the T3/T4 ratio (due to high T4), and selenium levels less than $10 \%\left(<10^{\text {th }}\right)$ of women in the control group. This finding indicated that in order to maintain adequate levels of T3, higher doses of L-thyroxine (T4) should have been given as a replacement therapy (Table 3 ). Poor selenium status at the $10^{\text {th }}$ percentile of $1.16 \mu \mathrm{mol} / \mathrm{L}$, lower than recommended, is associated with a diminished process of the peripheral deiodination, increased T4, and lower T3/T4 ratio. Selenium supplementation, with either selenium 
Table 3. The values of variables distributed in percentiles in both groups.

\begin{tabular}{|l|c|c|c|c|c|}
\hline Percentiles & $10^{\text {th }}$ & $25^{\text {th }}$ & $50^{\text {th }}$ & $75^{\text {th }}$ & $90^{\text {th }}$ \\
\hline Hypothyroid group on medication with L-thyroxine & \multicolumn{1}{l|}{} \\
\hline Age & 48.00 & 51.00 & 59.50 & 64.00 & \\
\hline TSH & 0.63 & 0.71 & 1.25 & 2.57 & \\
\hline T3 & $3.5^{*}$ & 4.10 & 4.35 & 4.72 & \\
\hline T4 & $14.00^{*}$ & 14.25 & 15.00 & $16.75^{*}$ & \\
\hline T3/T4 ratio & 0.23 & 0.24 & $0.28^{*}$ & $0.31^{*}$ & \\
\hline Selenium & $1.16^{*}$ & 1.23 & 1.29 & 1.46 & \\
\hline & & & & & \\
\hline Control group & & & & & \\
\hline Age & 40.60 & 46.50 & 54.00 & 58.50 & 62.80 \\
\hline TSH & 1.44 & 1.70 & 2.10 & 2.22 & 2.74 \\
\hline T3 & 4.02 & 4.20 & 4.90 & 5.10 & 5.74 \\
\hline T4 & 12.40 & 14.00 & 14.00 & $16.00^{*}$ & 16.60 \\
\hline T3/T4 ratio & 0.26 & 0.28 & $0.34^{*}$ & $0.35^{*}$ & 0.41 \\
\hline Selenium & 1.04 & 1.14 & 1.29 & 1.38 & 1.51 \\
\hline
\end{tabular}

selenite or SeMet, might be effective in slowing the progression of autoimmune thyroiditis (AIT), as reflected by the reduction of serum autoantibodies, with more or less success [55-59].

In regards to the relationship between creatinine and GFR which is purely physiological, estimates of GFR that are based on serum creatinine are routinely used for the assessment of kidney function, and/or creatinine excretion [60]. However, there is a link between serum creatinine and GFR genes to chromosome 2, meaning this region harbours a gene influencing phenotypic variation in serum creatinine and GFR [61].

\section{Conclusions}

This study had a relatively small sample size and provided important findings. Significant relationships between T3 and selenium, and age and T4 were identified in women with Hashimoto's thyroiditis. There was a moderate selenium deficiency in both of the groups that affected more women with hypothyroidism. Compromised peripheral deiodination in women with hypothyroidism required increased L-thyroxine dosing, which in turn increased the level of T4, and decreased pituitary TSH, in order to achieve the desired level of T3. To increase plasma selenium level, recent research has suggested that selenium supplementation with selenomethionine (SeMet) or selenium selenite might slow down the process of thyroid destruction by thyroid autoantibodies in Hashimoto's thyroiditis, through a decrease in autoimmune inflammation. The process of selenium supplementation has variable success rates in New Zealand and worldwide. Hence, further research is warranted.

Expert panels do not recommend screening of TSH for subclinical hypothyroidism of the general population, although ATA recommended screening in all adults beginning at the age of 35 years, including women of fertile age, and every 5 years thereafter, in order to postpone development of overt hypothyroidism and its morbidity.

\section{Acknowledgments}

I am very thankful for the financial support I received from the School of Interprofessional Health Studies, and help from my colleagues in the recruitment of participants. All participants in the study read the Participants Information Sheet and gave Written Consent. The Auckland University of Technology Ethics Committee (AUTEC) No. $13 / 17$, according to the Declaration of Helsinki, approved the study protocol.

\section{References}

1. Gibbons V, Conaglen JV, Lillis S, Naras V, Lawrenson R (2008) Epidemiology of thyroid disease in Hamilton (New Zealand) general practice. Aust $N Z J$ Public Health 32: 421-423. [Crossref]

2. Schimmel M, Utiger RD (1977) Thyroidal and peripheral production of thyroid hormones: review of recent findings and their clinical implications. Ann Inter Med 87: 760-768. [Crossref]

3. Fonseca TL, Correa-Medina M, Campos MP, Wittmann G, Werneck-de-Castro JP, et al. (2013) Coordination of hypothalamic and pituitary T3 production regulates TSH expression. J Clin Invest 123: 1492-1500. [Crossref]

4. Aaseth J, Frey H, Glattre E, Norheim G, Ringstad J, et al. (1990) Selenium concentrations in the human thyroid gland. Biol Trace Elem Res 24: 147-152. [Crossref]

5. Brown KM, Arthur JR (2001) Selenium, selenoproteins and human health: a review. Public Health Nutr 4: 593-599. [Crossref]

6. Kryukov GV, Castellano S, Novoselov SV, Lobanov AV, Zehtab O, et al. (2003) Characterization of mammalian selenoproteomes. Science 300: 1439-1443. [Crossref]

7. Köhrle J, Jakob F, Contempré B, Dumont JE (2005) Selenium, the thyroid, and the endocrine system. Endocr Rev 26: 944-984. [Crossref]

8. Rayman MP (2009) Selenoproteins and human health: insights from epidemiological data. Biochim Biophys Acta 1790: 1533-1540. [Crossref]

9. Castellano S, Lobanov AV, Chapple C, Novoselov SV, Albrecht M, et al. (2005) Diversity and functional plasticity of eukaryotic selenoproteins: identification and characterization of the SelJ family. P Natl Acad Sci USA 102: 16188-16193. [Crossref]

10. Papp LV, Lu J, Holmgren A, Khanna KK. (2007) From selenium to selenoproteins: synthesis, identity, and their role in human health. Antioxidants \& Redox sig 9: 775806. [Crossref]

11. Beckett GJ, Arthur JR (2005) Selenium and endocrine systems. J Endocrinol 184: 455465. [Crossref]

12. Duntas LH (2010) Selenium and the thyroid: a close-knit connection. J Clin Endocrinol Metab 95: 5180-5188. [Crossref]

13. Rayman MP (2000) The importance of selenium to human health. Lancet 356: 233-241. [Crossref]

14. Margis, R., Dunand, C., Teixeira, F. K. \& Margis-Pinheiro, M. 2008. Glutathione peroxidase family-an evolutionary overview. Febs Journal, 275, 3959-3970.

15. Gereben B, Zavacki AM, Ribich S, Kim BW, Huang SA, et al. (2008) Cellular and molecular basis of deiodinase-regulated thyroid hormone signaling 1. Endocrine reviews 29: 898-938. [Crossref]

16. Bianco AC, Kim BW (2006) Deiodinases: implications of the local control of thyroid hormone action. J Clin Invest 116: 2571-2579. [Crossref]

17. Silva JE, Dick TE, Larsen PR (1978) The contribution of local tissue thyroxine monodeiodination to the nuclear 3, 5, 3'-triiodothyronine in pituitary, Liver, and Kidney of Euthyroid Rats. Endocrinology 103: 1196-1207. [Crossref]

18. Larsen PR, Silva JE, Kaplan MM (1981) Relationships between circulating and intracellular thyroid hormones: physiological and clinical implications. Endocr Rev 2: 87-102. [Crossref]

19. Gereben B, Zavacki AM, Ribich S, Kim BW, Huang SA, et al. (2008) Cellular and molecular basis of deiodinase-regulated thyroid hormone signaling. Endocr Rev 29: 898-938. [Crossref]

20. Holtorf K (2014) Peripheral Thyroid Hormone Conversion and Its Impact on TSH and Metabolic Activity. J Restor Med 3: 30-52.

21. Little AG (2016) A review of the peripheral levels of regulation by thyroid hormone. $J$ Comp Physiol B 186: 677-688. [Crossref]

22. Schmutzler C, Gotthardt I, Hofmann PJ, Radovic B, Kovacs G, et al. (2007) Endocrine disruptors and the thyroid gland - a combined in vitro and in vivo analysis of potential new biomarkers. Environ Health Persp 115: 77. [Crossref]

23. Whanger P (1998) Metabolism of selenium in humans. J TraceElem Exp Med 1: 227 240

24. Burk RF, Hill KE (2005) Selenoprotein P: an extracellular protein with unique physical characteristics and a role in selenium homeostasis. Annu Rev Nutr 25: 215-235. [Crossref]

25. Xia Y, Hill KE, Li P, Xu J, Zhou D, et al. (2010) Optimization of selenoprotein P 
and other plasma selenium biomarkers for the assessment of the selenium nutritional requirement: a placebo-controlled, double-blind study of selenomethionine supplementation in selenium-deficient Chinese subjects. Am J Clin Nutr 92: 525-531. [Crossref]

26. Reeves MA, Hoffmann PR (2009) The human selenoproteome: recent insights into functions and regulation. Cell Mol Life Sci 66: 2457-2478. [Crossref]

27. Combs GF Jr (2015) Biomarkers of selenium status. Nutrients 7: 2209-2236. [Crossref]

28. Rayman MP (2005) Selenium in cancer prevention: a review of the evidence and mechanism of action. Proc Nutr Soc 64: 527-542. [Crossref]

29. University of Otago and Ministry of Health (2011) A Focus on Nutrition: Key findings of the 2008/09 New Zealand Adult Nutrition Survey. Wellington, New Zealand.

30. Rayman MP (2004) The use of high-selenium yeast to raise selenium status: how does it measure up? Br J Nutr 92: 557-573. [Crossref]

31. Mann J, Truswell S (2012) Essentials of human nutrition, Oxford University Press.

32. Thomson CD (2004) Assessment of requirements for selenium and adequacy of selenium status: a review. Eur J Clin Nutr 58: 391-402. [Crossref]

33. Canaris GJ, Manowitz NR, Mayor G, Ridgway EC (2000) The Colorado thyroid disease prevalence study. Arch Intern Med 160: 526-534. [Crossref]

34. Cooper DS, Biondi B (2012) Subclinical thyroid disease. Lancet 379: 1142-1154. [Crossref]

35. McDermott MT, Ridgway EC (2001) Subclinical hypothyroidism is mild thyroid failure and should be treated. J Clin Endocrinol Metab 86: 4585-4590. [Crossref]

36. Surks MI, Ocampo E (1996) Subclinical thyroid disease. Am J Med 100: 217-223. [Crossref]

37. Garber JR, Cobin RH, Gharib H, Hennessey JV, Klein I, et al. (2012) Clinical practice guidelines for hypothyroidism in adults: cosponsored by the American Association of Clinical Endocrinologists and the American Thyroid Association. Thyroid 22: 12001235. [Crossref]

38. Chakera AJ, Pearce SH, Vaidya B (2012) Treatment for primary hypothyroidism: current approaches and future possibilities. Drug Des Devel Ther 6: 1-11. [Crossref]

39. Galetta F, Franzoni F, Fallahi P, Tocchini L, Braccini L, et al. (2008) Changes in heart rate variability and QT dispersion in patients with overt hypothyroidism. Eur $J$ Endocrinol 158: 85-90. [Crossref]

40. Roberts CG, Ladenson PW (2004) Hypothyroidism. Lancet 363: 793-803. [Crossref]

41. Boeving A, Paz-Filho G, Radominski RB, Graf H, Amaral de Carvalho G (2011) Lownormal or high-normal thyrotropin target levels during treatment of hypothyroidism: a prospective, comparative study. Thyroid: J Am Thyroid Assoc 2: 355-360. [Crossref]

42. Vaidya B, Pearce SHS (2008) Management of hypothyroidism in adults. BMJ 337.

43. Laurberg P, Andersen S, Pedersen IB, Carle A (2005) Hypothyroidism in the elderly: pathophysiology, diagnosis and treatment. Drugs \& Aging 22: 23-38. [Crossref]

44. Pecina J, Bernard M, Furst J, Rohrer J (2012) Hypothyroidism management: is an annual check of TSH level always necessary? J Fam Pract 6: E1-5. [Crossref]

45. Mortoglou A, Candiloros H (2004) The serum triiodothyronine to thyroxine (T3/
T4) ratio in various thyroid disorders and after Levothyroxine replacement therapy. Hormones-Athens 3: 120-126. [Crossref]

46. Carr D, McLeod DT, Parry G, Thornes HM (1988) Fine adjustment of thyroxine replacement dosage: comparison of the thyrotrophin releasing hormone test using a sensitive thyrotrophin assay with measurement of free thyroid hormones and clinical assessment. Clin Endocrinol 28: 325-333. [Crossref]

47. Arthur JR, Nicol F, Beckett GJ (1990) Hepatic iodothyronine 5'-deiodinase. The role of selenium. Biochem J 272: 537-540. [Crossref]

48. Thomson CD, McLachlan SK, Grant AM, Paterson E, Lillico AJ (2005) The effect of selenium on thyroid status in a population with marginal selenium and iodine status. British j nutrition 94: 962-968.

49. Karunasinghe N, Han DY, Zhu S, Yu J, Lange K, et al. (2012) Serum selenium and single-nucleotide polymorphisms in genes for selenoproteins: relationship to markers of oxidative stress in men from Auckland, New Zealand. Genes \& nutrition 7: 179-190. [Crossref]

50. Burk RF, Norsworthy B K, Hill KE, Motley AK, Byrne DW (2006) Effects of chemical form of selenium on plasma biomarkers in a high-dose human supplementation trial. Cancer Epidem Biomar 15: 804-810. [Crossref]

51. Thomson CD (2004) Selenium and iodine intakes and status in New Zealand and Australia. Brit J Nutr 9: 661-672. [Crossref]

52. Rayman MP1 (2012) Selenium and human health. Lancet 379: 1256-1268. [Crossref]

53. Weetman AP (2012) The immunopathogenesis of chronic autoimmune thyroiditis one century after hashimoto. Eur Thyroid $J$ 243-250. [Crossref]

54. Weetman A (2000) Chronic autoimmune thyroiditis. Thyroid: a fundamental and clinical text. Philadelphia: Lippincott Williams \& Wilkins, 721-32.

55. Toulis KA, Anastasilakis AD, Tzellos TG, Goulis DG, Kouvelas D.et al. (2010) Selenium supplementation in the treatment of Hashimoto's thyroiditis: a systematic review and a meta-analysis. Thyroid, 20, 1163-1173. [Crossref]

56. Thomson CD, Campbell JM, Miller J, Skeaff SA, Livingstone V (2009) Selenium and iodine supplementation: effect on thyroid function of older New Zealanders. Am J Clin Nutr 90: 1038-1046. [Crossref]

57. Turker O, Kumanlioglu K, Karapolat I, Dogan I. (2006) Selenium treatment in autoimmune thyroiditis: 9-month follow-up with variable doses. $J$ Endocrinol 190: 151-156. [Crossref]

58. Gärtner R, Gasnier BCH, Dietrich JW, Krebs B, Angstwurm MWA, et al. (2002) Selenium supplementation in patients with autoimmune thyroiditis decreases thyroid peroxidase antibodies concentrations. J Clin Endocr Metab 87: 1687-1691. [Crossref]

59. Karanikas G, Schuetz M, Kontur S, Duan H, Kommata S, et al. (2008) No immunological benefit of selenium in consecutive patients with autoimmune thyroiditis. Thyroid: $J$ Am Thyroid Assoc 18: 7-12. [Crossref]

60. Inker LA, Schmid CH, Tighiouart H, Eckfeldt JH, Feldman HI, et al. (2012) Estimating glomerular filtration rate from serum creatinine and cystatin C. New Engl J Med 367: 20-29.

61. Hunt SC, Coon H, Hasstedt SJ, Cawthon RM, Camp NJ (2004) Linkage of serum creatinine and glomerular filtration rate to chromosome 2 in Utah pedigrees. $\mathrm{Am} \mathrm{J}$ Hypertens 17: 511-515. [Crossref]

Copyright: (C2017 Jowitt L. This is an open-access article distributed under the terms of the Creative Commons Attribution License, which permits unrestricted use, distribution, and reproduction in any medium, provided the original author and source are credited. 